\title{
Sameness, Definition, and Essence
}

\author{
Michail Peramatzis \\ Faculty of Philosophy, University of Oxford
}

I formulate an apparent inconsistency between some claims Aristotle makes in his Metaphysics about the sameness and non-sameness relations which obtain between an object and its essence: while a (type of) object is not the same as its essence, an essence is thought as being the same as its essence. I discuss different ways in which one may propose to overcome this apparent inconsistency and show that they are problematic. My diagnosis of the problem is that all these putative solutions share the assumption that Aristotle is operating exclusively with the notion of strict numerical identity between an object and its essence, or between definiendum and definiens. I introduce the notion of sameness in nature which holds between an object and its essence, understood as the metaphysical counterpart to the relation of 'being defined as': two items are the same in nature just in case the answer to the 'what is it?' or 'what is its nature/essence?' question is common to both. I argue that the notions of sameness in nature and 'being defined as' need not (but may) entail strict identity. Further, they are compatible with, indeed require, the idea that an essence is prior to its essence-bearer, or that a definiens is prior to the relevant definiendum. I conclude that the twin notions of sameness in nature and 'being defined as' successfully defuse the apparent inconsistency formulated at the outset.

Keywords: essence, definition, identity, sameness, priority

\section{Introduction: The Problem}

In Metaphysics Z.10-11 and H.3 Aristotle makes two important claims about the relation between a (type of) thing and its essence:

( $\mathrm{T} 1$ ) But the parts of the account are those of the form alone, while the account is of the universal; for being circle and circle, and being soul and soul are the same (Met. Z.10, 1035b33-1036a2).

Corresponding author's address: Michail Peramatzis, Worcester College, Walton Street, Oxford, OX1 2HB, United Kingdom. Email: michail.peramatzis@philosophy.ox.ac.uk. 
(T2) And [it has also been discussed that] the essence and each thing in some cases are the same, just as in the case of primary substances, as, for instance, curvature and being curvature, if this is a primary substance ... while in the case of those items that are as matter or are taken together with matter, they are not the same [as their essence] nor are they accidentally one [with their essence], as, for instance, Socrates and the cultivated thing; for these last are the same accidentally (Met. Z.11, 1037a33-b7).

(T3) For soul and being soul are the same, while being man and man are not the same, unless even the soul will be said to be a man; but this is so only in one respect but not in another (Met. H.3, 1043b2-4).

Thus, in (T1), at Z.10, 1036a1-2, he seems to claim that

(A/The?) soul and being a soul (a soul's essence) are the same (tauton).

(A/The?) circle and being a circle (a circle's essence) are the same.

In (T2), at Z.11, 1037a33-b5, it is claimed that in the case of primary substances (presumably essences or forms) each (type of) item and its essence are the same. For instance:

(A/The?) curvature and being a curvature (a curvature's essence) are the same.

In the case of "material" or "matter-involving" items, by contrast, each (type of) thing and its essence are not the same: a hylomorphic compound and its essence is such a case. For example:

Socrates and being Socrates (Socrates' essence) are not the same.

And in $\left(\mathrm{T}_{3}\right)$, at H.3, 1043b2-4, Aristotle offers an example similar to that used in Z.10:

(A/The?) soul and being a soul (a soul's essence) are the same.

(A/The?) human and being a human (a human's essence) are not the same.

The reason he provides to support this last claim is that a (the?) soul is not (a?) human.

There is a way in which to generate an apparently inconsistent set of claims from Aristotle's remarks. Let us, for present purposes, limit the scope of the expression '(type of) thing' to what Aristotle calls "universal compounds" at Metaphysics Z.10, 1035b27-30. These are substance-kinds, types 
of object or type-objects (e.g., species) such as human or horse. Aristotle argues that they are not (primary?) substances but are constituted from form and matter taken universally. Further, let us employ as an example of such a substance-kind the type human. ${ }^{1}$ As an example which typifies the case of a soul invoked at Z.10, 1036a1-2, a paradigmatic case of essence or form, we could use the essence or form being a human (or, equivalently: to be a human; what-it-is-to-be a human). The passages just quoted would suggest that, while the type human is not the same as its essence, being a human:

(1) Human $\neq$ being a human,

the essence or form being a human is the same as its essence. Suppose, for example, that the essence of being a human is being a rational soul:

(2) Being a human = being a rational soul.

At Metaphysics Z.10, 1035b33-1036a1, as well as Z.11, 1036a28-29, this last claim is linked with the primary role of essence or form in definition: "definition is of the form (and the universal)". Let us, for the sake of argument, assume that this remark at least allows that essences or forms are definable. ${ }^{2}$ Hence:

(3) Being a human $=_{d e f}$ being a rational soul. ${ }^{3}$

I take the symbol ' $=$ def ${ }^{\prime}$ to be signifying the relation of being defined as. If this is correct, the context of $\left(\mathrm{T}_{1}\right)$ and $\left(\mathrm{T}_{2}\right)$ suggests that sameness (understood as identity, in the manner of (2)) entails a definitional relation such as that

1 I shall return to particular compounds, individual objects, and the relation to their essence in section 10 .

${ }^{2}$ I shall take up this important point in section 4.

3 Claims (2) and (3) raise the important question of whether an essence or form itself has an essence or form, or whether it is itself definable (as opposed to merely being what does the defining). There are two related worries in this connection. First, (2) and (3) might be thought as giving rise to the absurd idea that there is an essence of an essence, a form of a form, or a definition of a definition. Second, this idea seems vulnerable to an infinite regress: if the essence of the essence being a human is being a rational soul, then why not think that there is an essence of the essence being a rational soul? But if so, why not proceed in a similar manner ad infinitum? One way in which to resolve this difficulty is to exercise caution in understanding phrases such as 'the essence of an essence' or 'an essence has its essence' etc. The italicised terms in such phrases are to be construed metaphorically. They do not have the same meaning as the claims expressing the relation between (types of) objects, the standard essence-bearers, and their essences. An essence does not have an essence in the way in which a (type of) object has an essence which is distinguishable from, and metaphysically prior to, it. Rather an essence "has" an essence in that it is (identical with) an essence. This strong identity claim blocks the infinite regress worry. This question will be taken up in section 4 . 
in (3). ${ }^{4}$ But the entailment seems to run in the opposite direction too: for if $x$ is defined as being $F$, it follows that $x$ is somehow the same as being $F$. If this sameness relation is understood as identity, (3) would also entail (2).

At the same time, however, Aristotle holds that substance-compounds are definable (see, e.g., Met. Z.4, 1030a11-14: genous eidé; Z.11, 1037a2829; Z.12, 1037b10-13; 1038a28-32; Z.17, 1041a2o-21; 26-27; 32-b7; and elsewhere). ${ }^{5}$ With the restriction to substance-kinds or type-objects in place, this suggests that:

\section{(4) Human $=_{d e f}$ being a human. ${ }^{6}$}

Given the mutual entailment between definitional and sameness relations just discussed, (4) would imply:

(5) Human = being a human.

This last claim, though, clashes with (1). Alternatively, it may be thought that a definitional relation such as that codified in claims (3) and (4) does not entail sameness or identity. Indeed, a stronger claim might be made: definitions such as (3) or (4) entail a non-identity relation between the definiendum and the definiens. But if this is correct, from (3) it would follow that:

(6) Being a human $\neq$ being a rational soul.

In this case, though, there is an inconsistency between (6) and (2). The question I shall address in what follows is what (if any) would be the (exegetically

${ }^{4}$ In section 8 I shall argue that the most promising way in which to resolve the inconsistency described in the present section is by revising the sameness and the definitional relations so that they do not entail identity.

${ }^{5}$ My references to Metaphysics Z.17 might be thought as falling short of showing that substance-kinds such as human are definable. For, it might be argued, in that chapter Aristotle does not focus on the question of what a human is but of why a human is thusand-so, or why a certain structure belongs to (human) flesh, bones, etc. If so, he raises only certain causal-explanatory but not any definitional questions about substance-kinds. This objection is not sensitive to Aristotle's project in Metaphysics Z.17. In this chapter he seeks to extend the Analytics model of explanation and definition of process-types (such as thunder or eclipse) to substance-kinds. This model relies on the thesis that explanation and definition are interdependent, for the causal structure of a phenomenon and its nature or essence are interdependent. Indeed, at Met. Z.17, 1041a27-32, he argues that the essence of a house or a human (what is picked up by a definiens-expression) is the cause of these kinds (or: the cause of these kinds' being what they are). Hence, the question 'why is a human thus-and-so?' as well as the answer to it are intrinsically linked to the question 'what is the kind human?'. If so, Aristotle takes such substance-kinds as definable.

6 There is no need, for present purposes, to discuss whether, in Aristotle's view, a substancekind is defined per genus et differentiam, or in terms of form and matter, or on the basis of potentiality and actuality, or what have you. For simplicity, I shall use only the hylomorphic model. 
and philosophically) most plausible way in which Aristotle could overcome this (apparent?) inconsistency.

\section{Denying (1)}

Apart from the obvious exegetical cost, denying that a substance-kind or type-object is non-identical with its essence has a serious conceptual implication if indeed this denial is equivalent to the idea that a substance-kind, or generally an essence-bearer, is identical with its essence. First, it would be odd to identify the compound whole with one of its proper parts (its essence or form). It seems more reasonable, then, to hold that the compound is nonidentical with its essence. ${ }^{7}$ More importantly, our intuition is that an essence is metaphysically prior to its essence-bearer in that it makes the latter what it is but not conversely. But if the relation between an essence-bearer and its essence were identity, this intuition would have to be given up. ${ }^{8}$ For identity is a symmetric relation, while priority is asymmetric, and no relation can be both symmetric and asymmetric (in the very same way or sense). It is, therefore, important to retain (1) as it allows for (but is not equivalent to) the priority of essence over the relevant essence-bearer.

\section{Denying (2)}

One might hold that an essence or form such as being a human is not the same as its essence, being a rational soul, just as in (1) a substance-kind or object-type is not the same as its essence. This approach, however, is not sensitive to Aristotle's way of distinguishing between essence and compound in (1) and (2): in it the essence or form turns out to be different from its essence, just as the compound is different from its essence. But if so, we seem to be at a loss as to what the difference is between essence (or form) and compound in respect of their relation to their respective essences. Further, this option would not be a plausible way in which to formulate Aristotle's claim that the soul, a par excellence case of essence or form, is the same as being a soul (Z.10, 1036a1-2).

Alternatively, one could argue that some but not all cases of essence or form are the same as their essence. It would be difficult, though, to provide a criterion with which to determine which cases of form comply with

7 I am indebted to Riin Sirkel for this point.

8 This intuition need not influence our view of (2). For, as noted earlier (in footnote 3), an essence or form (as understood in the present study) does not have an essence in the way in which a (compound) object or a kind does: being a rational soul is not an extra, metaphysically prior entity had or possessed by being a human; rather being a rational soul just is (identical with) the relevant essence, being a human. I shall return to this point in section 4 . 
(2) and which do not. One suggestion (perhaps motivated by Aristotle's remarks about being a circle and being a curvature at Z.10, 1036a1-2, and Z.11, 1037 b2-3) might be that a mathematical essence or form is the same as its essence, whereas a natural essence or form is not. But why should this be the case? And even if it is, how are we to understand Aristotle's claim that the soul (which is not a mathematical but is a natural form; see Met. E.1, 1026a1-6) and its own essence, being a soul, are the same?

Irrespective of Aristotle's view, however, it seems correct to think that an essence or form just is (identical with) an essence, "its" essence or the essence it "has", that is to say the essence that it simply is. There is no need, indeed it would be mistaken, to think that this requires the presence of two distinct entities, an essence-bearer plus a metaphysically more fundamental essence had by it. Rather, there is just one entity, an essence or form such as being a human, expressed in two different ways: a shorter, perhaps more opaque way, being a human, and a more elaborate, perhaps more perspicuous or informative way, being a rational soul. There is good reason, then, to hold firm to (2).

\section{Denying (3)}

Another strategy would be to deny that an essence or form is definable or/and that it has an essence. Similarly, one could maintain that while an essence or form is definable, it is not definable in terms of its essence as it lacks an essence. Thus, for instance, one could provide necessary and sufficient conditions for being a human, perhaps using an expression which is necessarily co-extensive with 'being a human', and so somehow "define" being a human. One could not, however, offer a definition in terms of any essence of the entity being a human: for being a human just is not the sort of entity that has an essence. This approach relies on a deflationary view of definition, one which does not require that a correct definiens be an account of the definiendum's essence. But Aristotle's view of definition is more demanding than this. It presupposes that a correct definition is an account of the definiendum's essence (a logos tès ousias or tou ti èn einai; see, for example, Met. Z.4, 1029 b2O; 25-27; 1030a6-7). For, in his view, a definition describes precisely what makes the definiendum what it is, i.e. its very essence or nature (see Met. Z.4, 103oa3-6: hoper tode ti; cf. APo I.4, 73b7-8; I.19, 81b25-29; I.22, 83a24-32: hoper ekeino ti).

The underlying assumption shared by the different variants of the approach under discussion is that there is something paradoxical about the idea that an essence has an essence, or that a form has a form, or that a definition (which ultimately picks up an essence or form) has a definition. Moreover, this idea seems to give rise to an infinite regress. If an essence, 
such as being a human, has an essence of its own, such as being a rational soul, there is nothing which prevents us from seeking a further essence, to be had by being a rational soul, and so on and so forth ad infinitum. Similarly, if there are 'essences of essences', and a definition describes an essence in its definiens, it would be possible to extend the definitional task infinitely: for there would be a further definiens describing the essence of the essence picked up by the first definiens, and so on and so forth ad infinitum.

These are not insurmountable difficulties for (3). As I noted en passant earlier, these difficulties presuppose that the essence on the right-hand side of (2), also picked up by the definiens-phrase in (3), "belongs to" or "is had by" the essence on the left-hand side of (2), the referent of the definien$d u m$-term in (3), in the very same way in which a (type of) object, a typical essence-bearer, has an essence in (1), the essence picked up by the definiensexpression in (4). This is not a compelling presupposition. It seems straightforward to think that 'to have' in the phrase 'has an essence' and the possessive case in phrases such as 'the essence of the essence' are used non-literally when applied to essences themselves. These phrases do not indicate that there is an extra, metaphysically distinct, and more basic entity which is somehow possessed by an essence as its "further" essence, and which is prior to it or makes it what it is. Rather, the idea is that an essence, such as being a human, just is the essence being a rational soul: for it is strictly identical with it. This move seems to defuse the twin worries about "the essence of an essence" and the infinite regress of essence, form, and definition. In what follows, I shall use the odd phrase 'essence of an essence' as sparingly as possible. This expression should not, at any rate, be understood as introducing a further, prior entity to be had by an essence. Rather, it picks up the very same essence itself, for instance, being a human, cast in a more elaborate or perspicuous fashion, for example, as being a rational soul. ${ }^{9}$

Aristotle himself seems to favour some version of (3). For, at Metaphysics Z.10, 1035b33-1036a1, and Z.11, 1036a28-29, he maintains that definition is "of the form and of the universal". There are several questions raised by this pivotal but obscure remark. Does this claim suggest that definition is of the form (and the universal) alone or predominantly? Further, does it entail that the only (or primary) object of definition (the only or primary legitimate definiendum) is the essence or form, or is the restriction intended to ap-

9 Lowe $(2008,34)$ too argues that an essence does not have an essence as it is not an entity; see also (Shalkowski 2008) for comments on Lowe's paper. I agree with Lowe's claim, if by 'entity' he means 'object' or 'particular object'. I think, however, that essences (at least in Aristotle's view) are real, and so 'entities' in a way different from that in which particular objects are entities. This does not, in any way, require that Aristotelian essences turn out to be independently existing entities or quasi-Platonist Forms. I am indebted to Tuomas Tahko for drawing my attention to Lowe's view. 
ply to the definiens, what exclusively or primarily does the defining? Or is Aristotle's view some type of coherent combination or compromise between some of the alternatives just adumbrated?

There is evidence that Aristotle does not take essence or form as the only or even primary definiendum. For he takes compounds and matter as definitionally posterior to essence and form (Z.10, 1035b4-22). Since he spells out definitional posteriority as the asymmetric relation in which an item is defined in terms of another but not conversely (Z.10, 1034b3o-31; 1035b4$11 ;$ M.2, 1077b3-4), he must think that compounds and matter are somehow definable in terms of essence and form but not conversely. If this is correct, there are other items, besides essence and form, which are possible objects of definition: compounds and matter.

It seems more plausible, then, to think that essence or form is the ultimate or fundamental definiens in terms of which other items (such as compounds or matter) are defined. This need not imply anything stronger than the claim that a definition is fundamentally shaped in terms of an essence or form picked up by the definiens. Does this preclude out of hand that an essence or form is itself a possible definiendum, such that it cannot be on the left-hand side of claims such as (3)? Not necessarily. At Metaphysics H.3, 1043a29-36, Aristotle contends that terms such as 'house' or 'animal' may signify not the compound but the essence, form, or actuality. For instance, 'human' may signify the same as 'being a human' in our (2). At the same time, though, he claims that the essence or form of a house is to be a shelter, and the essence or form of a (human) animal is to be a (human or rational) soul. This suggests that an essence or form can be further defined in the manner of our (3): human, understood as the essence being a human, can be further "unpacked" in a definition in terms of (e.g.) being a rational soul.

This is the intuition underlying (3). This definitional claim is legitimate, for an essence such as being a human can be set out in terms of a more elaborate or more illuminating account, such as (e.g.) being a rational soul. This definiens does not pick up any additional entity, a distinct essence which is prior to being a human. Rather, it picks up the very same entity, the essence being a human, perhaps expressed in an epistemically more transparent or intelligible fashion. Thus, while being a human = being a rational soul, the definition in terms of being a rational soul seems unproblematic provided that what is picked up by the definiens-expression is not a distinct or prior entity but simply the same essence, described in an epistemically more basic guise. 


\section{Denying (4)}

Another attempt at resolving the inconsistency would be to deny that compounds (substance-kinds, type-objects, or generally essence-bearers) are definable. This desperate approach might be motivated by Aristotle's cryptic claim that particular compounds, objects such as Socrates or Bucephalus, are not definable (or indeed knowable; Z.10, 1036a2-9; Z.11, 1037a25-30; Z.15, 1039b27-1040a7). A proponent of this approach might think that this claim carries over to universal compounds too, such as the substance-kind human in (1) and (4). A more cautious reading of the relevant passages, however, not only suggests that universal compounds or substance-kinds are paradigmatic objects of definition (occupying the definiendum position; see, e.g., Met. Z.4, 1030a11-14: genous eidē; Z.11, 1037a28-29; Z.12, 1037b10$13 ; 1038 \mathrm{a} 28-32 ; Z .17,1041 \mathrm{a} 20-21 ; 26-27 ; 32-b 7$; and elsewhere). It even allows that particular compounds may be definable in a certain way: in terms of the essence or form of the substance-kind they are members of (Z.10, 1036a7-8; Z.11, 1037a28-30).

A more refined version of this strategy would be to claim that there is a fundamental difference between the sameness and definitional relations obtaining in the case of an essence or form and those applying to substancekinds or type-objects. Hence, an essence or form is defined purely in terms of its essence, or the essence it is, without any addition or subtraction of anything. If so, a definition such as (3) does indeed march in step with a sameness claim such as (2). For the definiens just is the definiendum in (3), and so the identity reading of the sameness claim in (2) is correct. In the case of a substance-kind, by contrast, the definiens in (4) adds to or subtracts from the definiendum (as the case may be) some item, and so cannot entail, or be entailed by, an identity claim such as (5). Rather, it allows only for a non-identity such as (1). For in (4) the definiens is something "more" or something "less" than the definiendum, and so no identity claim can obtain on the basis of such a definition.

Clearly, the major question to be raised, at this juncture, is why definitions of substance-kinds proceed in this fashion of addition or subtraction, and what the nature of these definitional operations is. A suggestion might be that an essence or form is matter-free or purely "formal", and so is defined in a parallel purist fashion, without any need for adding to or subtracting from it anything. A substance-kind, by contrast, is a type of material object and so in defining it one has to deal with its material character. If one judges that the relevant matter is definitory of the type, one has to add this matter to the type's essence or form and construct an inflated definiens which picks up the type's essence or form plus its matter. But if one thinks that this matter is not to be mentioned in the type's definition, one subtracts the matter from 
it, and so one produces a "light" definiens in terms of the type's essence or form minus its matter.

The assumption inherent in this approach is that essence and definition do not, or need not, mirror each other. For the adding operation presupposes that, whereas the type-object is essentially (I take it) immaterial, its definition has to add a reference to non-essential (but perhaps merely necessary?) material items. The reason for the addition may be an underlying view of definition in which a definiens-expression should mention nonessential but merely necessary features over and above the essence or form. The subtracting route, on the other hand, takes the type-object as essentially material but treats its definition as an "essence/form only" affair. Perhaps the motivation behind this is Aristotle's claim that definition is of the form and the universal (Z.10, 1035b33-1036a1; Z.11, 1036a28-29). Proponents of subtraction would construe this claim as 'definition is of the form and the universal alone. They would also think that matter cannot have any formal or universal specification. They would, therefore, feel compelled to rescind it from the definiens.

Aristotle's answer to addition and subtraction would be that they simply fail to capture the essence of the definiendum. If so, they fail to serve the role of a successful definition: to be an account of the definiendum's essence. Regardless of whether we treat matter as essential to a substance-kind or not, if we deem anything essential to the definiendum, we have to mention it in but not subtract it from the definiens. Similarly, if anything is non-essential to the definiendum, it should not be added to the definiens. While Aristotle's argument in Metaphysics Z.4-5 is far from being straightforward, it clearly indicates that definitions by addition or subtraction are unsuccessful as they do not describe what the definiendum is in itself (kath' hauto) or essentially (to ti èn einai tini/toutōi; see. Z.4, 1029b18-19; 28-1030a2; Z.5, 1030b14-28; 1031a2-11).

Conceptually, too, the idea that a definition mirrors an essence precisely, adding nothing non-essential or subtracting nothing essential, seems attractive. A definition which invokes non-essential items or omits essential features fails to describe what the definiendum is precisely (see the hoper in the hoper tode ti and hoper ekeino ti locutions at Met. Z.4, 1030a3-6; APo I.4, 73b7-8; I.22, 83a24-32). This may render a definition explanatorily inadequate: for it would not explain in virtue of what the definiendum is as it is, or what makes it the type of thing it is. Or it may lead to flagrant falsities in which the definiendum- and definiens-expressions are plainly not co-extensive.

It should be noted that the requirement that a definiens-phrase should pick up that item which makes the definiendum what it is (and so an item 
which is metaphysically prior to, but not identical with, the definiendum) need not clash with the idea that a definition implies a sameness claim. The fact that the definiens is prior to the definiendum is compatible with a sameness relation between the two, provided that this sameness relation is not strict identity. In section 8 I shall suggest a way in which to understand Aristotelian sameness without equating it with identity.

\section{Denying the Entailment from (4) to (5)}

It could be argued that we are not warranted to infer any sameness or identity relation from a definition such as (4). Nor should we make any inferences in the opposite direction: for a non-sameness claim such as (1) may well be compatible with a definition such as (4), or indeed entail it. That is, the nonsameness between a type-object and its essence could still allow for, or even imply, a definition of the former in terms of the latter. The move from (4) to (5) is not cogent.

The first difficulty with this line is that it may suggest that in the case of (2) and (3), too, it would be incorrect to infer any sameness or identity from a definition, or conversely. But this seems exegetically unmotivated and, at any rate, incorrect. If the definiens of an essence or form-or any definiendum, for that matter-is to be $F$, this definiendum is (in some way) the same as to be $F$. The present approach could reply by distinguishing between cases in which the entailment (or even equivalence) holds and those in which it does not apply. Hence, for instance, it may be thought that, whereas in the case of an essence or form definitional and sameness relations are bi-conditionally linked, in the case of type-objects it is not the case that a definition entails a sameness claim (or vice-versa). This reply is artificial. It also lacks any textual support: Aristotle deploys the notion of sameness and non-sameness (tauton; ou tauton) for both essences and compounds in the very same context without signalling any shift in the meaning or the implications of the term 'tauton'.

There is a further question, though, about what exactly the denial of the entailment amounts to. In holding that we should not derive (5) from (4) are we asserting simply that it is not the case that a definition entails a sameness claim between definiendum and definiens? Or is this denial equivalent to a stronger claim in which a definition entails a non-sameness claim about the definiendum and the definiens? While the former approach may still render definitions compatible with (but not grounds for) sameness relations between the relevant definiendum and definiens, the latter, stronger view treats definitions as straightforwardly entailing non-sameness claims such as (1).

Apart from the obvious problem raised by the plausible link between (2) and (3), this view just seems too strong. For we would wish to retain 
the possibility that some definitions do not preclude out of hand a sameness relation between the definiendum and the definiens. Indeed, we may argue that all definitions at the very least allow for such a sameness relation, even if this relation cannot be read off from them alone or automatically. Thus, for example, we may hold that, with certain conservative grammatical reformulations, a definition may be transformed into a claim that strongly supports the definiendum-definiens sameness or identity claim.

Here is an indication as to how to make these last abstract suggestions more concrete. While one may hold firm to (1) and (4), thereby denying (5), one may re-read (4) as follows:

(7) Human ${ }_{\text {def }}$ the type of object whose essence is to be a human.

This seems derivable from (4). But (7) also seems to support, or at least be compatible with, the following claim:

(8) Human = the type of object whose essence is to be a human.

For what else is the kind human if not identical with the type of object the essence of which is to be a human (or being a human; or what-it-is-to-be a human)? We could formalise this approach by regimenting a 'the' operator which objectifies or type-objectifies the predicates it is pre-fixed to. Thus, when 'the' is introduced before the essence-specifying predicate 'being a human', it transforms it into a type-object phrase such as 'the type of object with the essence being a human'. The move from a definition such as (4) to an identity such as (8) via the minimal route of the 'the' operator in (7) seems innocuous and attractive. There is no reason, therefore, to block the inference from definition to sameness (or conversely) or, worse, to assert that a definition necessarily implies non-sameness.

\section{Unilateral Revisions of Definition or Sameness}

Perhaps a more principled way in which to block the implication from (4) to (5) would be to revise the notion of definition governing (3) and (4). In this view, a definitional relation should not be linked with sameness or identity in any way. It does not entail, nor is it entailed by, sameness or identity. Thus, (3) and (4) tell us nothing about the "identity conditions" of the definiendum or its sameness relations to anything. It is true, as (2) states, that an essence or form is the same as, or identical with, its own "being". But this is not to be derived from the definition of an essence or form. Nor does (2) point to any definition of an essence or form along the lines of (3). The theoretical grounds for this approach may consist in the idea that a definition is a linguistic item or a mere description which at best helps knowers such as ourselves to pick up or grasp the definiendum. This sort of epistemic role, 
however, does not reflect the real nature, the identity, or the sameness relations of the type-object, the real-world entity picked up or described by a defining formula. No sameness or identity claims, then, should be read off from any definition.

A similarly "unilateralist" approach would be to revise sameness or/and identity in a way which would divorce them from any definitional constraints or implications. Thus, one could maintain that (1) and (2) tell us nothing about the definitions of an essence such as being a human or a substancekind such as human. The motivation for this may be coming from a deflationary view of sameness or even identity, one which renders it virtually equivalent to necessary co-extensiveness. The proponent of this view would understand sameness or non-sameness claims such as (1) or (2) analogously to examples such as the following:

$$
\begin{aligned}
& \text { The evening star = the morning star. } \\
& \text { Human = animal capable of laughing. } \\
& \text { Socrates = Plato's teacher. }
\end{aligned}
$$

In all these examples of sameness or identity it would be misleading, counterintuitive, or even plainly mistaken to infer any corresponding definitions. The morning star, the evening star, or Venus would be defined in terms of (for instance) being a planet in our solar system having a certain position, orbit, mass, etc. The kind human would be defined not in terms of any of its merely necessary propria such as its risibility, but in terms of (for example) being a rational biped animal or being a rational soul. Similarly, Socrates would be defined, arguably, as essentially a member of the human kind and so in terms of that kind's definition. Deriving definitions from sameness or identity claims is an unwarranted move.

The weakness implicit in this view is that it is not sensitive to the distinctive type of sameness or identity statements that (1) or (2) constitute. In both cases Aristotle affirms or denies an item's sameness or identity with its own essence: a human and being a human; or soul and being a soul. He does not put forward claims about sameness or non-sameness obtaining between an item and whatever is picked up by a definite description of, or another proper name for, it. Nor is he interested in an entity's sameness or nonsameness with one of its merely necessary peculiar features (propria). His focus on essence and his contention that a (successful or correct) definition is an account of the definiendum's essence suggest that he would not disassociate sameness from definition in the manner suggested by our unilateral revisionist. Aristotle's non-sameness and sameness claims, (1) and (2), are about the essence of the item in the left-hand side of the two formulae. 
An essence is what fundamentally defines those items, what is picked up by the definiens-phrases of definitions such as (3) and (4). The two pairs of claims, then, should mirror each other. It seems that both types of unilateral revisionism - whether of definition alone, or of sameness alone-fail to capture Aristotle's considered position.

\section{Fine-tuning Sameness and Definition}

To offer a more promising solution to the apparent inconsistency noted in the introduction it seems reasonable to start by rejecting this last strategy of the unilateral revisionist. Aristotelian sameness (or "essence-sameness") and definition seem closely interwoven. If an item is essentially the same as being $F$, then being $F$ defines this item. Conversely, too, what is picked up by a definiens-phrase is essentially the same as what is referred to by the corresponding definiendum-term of a given definition. This, however, is just to bite the bullet about the clash of (1) with (4) and (5): why is the kind human not the same as its essence despite the fact that this kind is indeed defined in terms of that very essence?

An assumption shared by all strategies discussed so far, indeed an assumption which underlies the very formulation of our puzzle, is that Aristotle's essential sameness and non-sameness claims are translatable (respectively) into strict identity and non-identity statements such as (1) and (2). Similarly, definitions such as (3) and (4) are viewed as corresponding to sameness claims understood in terms of strict identity. But is the move from sameness or definition to identity cogent? Is there any logical space for a view of essential sameness and definition which is not identity-laden?

In section 2 I noted that a reason why (1) seems plausible is that the essence being human is metaphysically prior to, and so non-identical with, the kind human. Identifying the kind with its essence would discard this intuition of asymmetry. For it would be in tension with the idea that an essence makes the essence-bearer what it is, while the converse does not hold good. But this notion of metaphysical priority also governs definitional claims such as (4). ${ }^{10}$ Thus, the definiens being a human is metaphysically prior to the definiendum human: for the kind's essence, being a human, picked up by the definiens-formula, is that in virtue of which the kind human is what it is but not conversely. It seems that the priority of essence over essence-bearer and the priority of definiens over definiendum are just two sides of the same

${ }^{10}$ In section 4 I argued that metaphysical priority need not, indeed should not, apply to claims such as (2) or (3). For in such cases we are not dealing with two distinct entities, an object or essence-bearer plus its essence (or the essence it has) but with just one and the same entity, an essence such as being a human, also understood as being a rational soul. But being a human $=$ being a rational soul. 
metaphysical coin.

This idea sets an important constraint upon our understanding of essential sameness and definition. To allow for the priority of essence over essence-bearer and of definiens over definiendum, essential sameness and definition must not be equivalent to, or entail, identities. For, if they were straightforwardly translatable into identities, they would become congruence and equivalence relations just as identity is. Thus, they could not be asymmetric and so could not meet a basic requirement for priority. This does not imply that (1) and (2) are to be discarded altogether. (1) and (2) may still be true but not because of any definitional or essential sameness claims. Perhaps, they are true on independent grounds. Hence, for example, an essence or form may be identical with "its" essence just in virtue of the nature of the referents of the two expressions flanking the identity sign. Similarly, a substance-kind or type-object may be non-identical with its essence just because it is of an ontological category different from that of an essence. I shall return to this point in section 9. It is important to emphasise, at any rate, the possibility that neither essential sameness nor definition are tantamount to strict identity.

In this view of essential sameness and definition, it is plausible to think that, while identity may entail essential sameness and definition, it is not the case that essential sameness or definition entails identity. This last claim is not to be confused with the stronger view, which holds that essential sameness or definition entails non-identity. For instance, consider (2): being a human (the essence of the kind human) is identical with "its" essence, being a rational soul. Indeed, they are one and the same entity. This entails (3): being a human is defined in the terms of the essence being a rational soul. It also entails that being a human and being a rational soul are essentially the same: for to be a human is nothing other than, or is essentially the same as, being a rational soul. By contrast, while the essence of the kind human is being a human, and the kind is defined in terms of being a human, it does not follow that the kind human is identical with the essence being a human.

This suggests that some cases of essential sameness and definition allow for identity, whereas some others do not. Being a human is essentially the same as, and is defined in terms of, being a rational soul. But it is also the case that being a human is identical with being a rational soul. If so, the essential sameness and definitional relations obtaining between the two should not rule out identity. On the other hand, the kind human is defined in terms of being a human, and is essentially nothing other than, or is essentially the same as, being a human: for what else is to be (a member of) this kind other than to be a human? But it is not true, nor does it follow from those essential sameness and definitional relations that human = being a human. It is 
possible, to be sure, to use the device of the 'the' operator outlined in section 6 , and derive from these two relations the identity 'human = the type whose essence is to be a human'. But this is not the same identity statement as 'human = being a human' (or so I shall argue in section 9).

It seems true that essential sameness and definition entail necessary coextension between the relevant terms picking up essence and essence-bearer or definiens and definiendum. But necessary co-extension is by no means the whole story about essential sameness and definition. For the relation of necessary co-extension also obtains between the terms corresponding to a kind and its propria. Thus, for instance, whereas all and only humans (necessarily) are capable of laughing, being capable of laughing just doesn't seem to be the essence of the kind human. Essences are not mere propria.

To fill in the gaps of the present account of essential sameness and definition it seems promising to pursue the idea discussed earlier in the present section about being "essentially nothing other than" or "essentially the same as". A notational variant of this idea would be the notion of "non-difference" or "sameness in nature". The concept of (essential) sameness and definition being sought after is one in which the answer to the 'what is it?' or 'what is its essence/nature?' question, when asked about the two relata, is common to both. ${ }^{11}$ Being a human and being a rational soul are the very same essence, just one entity, and so must "have" the very same nature or essence, one 'what-it-is' and a common definition. The kind human and being a human do not seem to be the very same entity: they are not identical. For,

${ }^{11}$ David Charles introduces a similar relation in his interpretation of Metaphysics Z.6. He also argues that this relation is not to be understood in terms of (strict numerical) identity (cf. Charles 2011). The relation of sameness in nature should be distinguished from that of likeness in nature discussed by Zylstra in the present volume (2014, sections 1.2 and 5). Likeness in nature, as Zylstra understands it, seems to obtain between particulars which have the same nature and are essentially characterised by the same substance-kind term. Thus, for instance, Socrates and Plato are alike in nature in that both are (essentially) humans (or members of the kind human). Aristotle would normally conceive of this relation as oneness or sameness in (substance-) kind (see, e.g., Met. B.4, 999b24-10ooa4; B.6, 1002b12-32; M.10, 1086b22-27, where Aristotle contrasts oneness or sameness in number (arithmōi) with oneness or sameness in kind (eidei)). There is no incompatibility between sameness in nature, as I understand it, and Zylstra's likeness in nature. There are, however, two important differences between the two relations. First, while sameness in nature holds between an essence-bearer and its essence, an item which is not a member of the relevant substance-kind, likeness in nature holds between (particular) objects which are members of the same (substance-) kind. Second, sameness in nature presupposes that the correct logical form of an answer to the 'what is it?' question is given along the lines of 'being $F$, 'to be $F$, or 'what-it-is-to-be $F$, an expression which picks up an essential way or mode of being, an Aristotelian ti èn einai or essence (see section 9). Likeness in nature, by contrast, takes the logical form of such an answer to be ' $F$ ' or 'the $F$ ', a phrase which picks up a substance-kind, one of the secondary substances of Aristotle's Categories. 
as I remarked earlier, being a human is prior to, and so non-identical with, the kind human. But what-it-is-to-be the kind human and being a human seem to be the same in essence or nature: to be the kind is essentially nothing other than to be a human. Both the kind and the essence are defined in terms of being a rational soul. This does not imply that the kind is identical with its essence, and so is not inconsistent with (1). Nor, however, does it rule out an identity statement along the lines of (8), with the help of the 'the' operator inserted in (4). For the definition of the kind human in terms of being a human can, without any radical transformation, be recast as 'human $={ }_{\text {def }}$ the kind whose essence is to be a human'. But this last definition, our (7), seems straightforwardly to yield (8): human = the kind whose essence is to be a human.

\section{Ontological Excursus}

The basic ideas underlying the present view of essential sameness and definition are the following two. First, the metaphysical priority of essence over essence-bearer and of definiens over definiendum suggests that the relation between the two items is non-identity. Second, despite this non-identity aspect of essential sameness and definition, the two relata may or may not be identical in virtue of their own nature. Or they may or may not be identical because of further, additional features they possess. At any rate, their identity or non-identity would not be grounded on their essential sameness or/and definitional relations as such.

Both of these crucial points give rise to the question of how to understand the relata involved in essential sameness or definitional claims such as (1)-(4). Aristotle's ontology is populated mainly by what he calls "particular compound substances" (hylomorphic compounds) and "universal compounds" (consisting of form and matter "taken universally"); matter and material parts; essences or forms and their parts. Aristotle also holds that an essence or form is metaphysically and definitionally prior to the relevant (particular and universal) compounds and matter: an essence or form makes these posterior items what they are (but not conversely), and so they are defined in terms of it (but not conversely).

The crucial question, however, is what general ontological category an essence or form belongs to. Clearly, this "generic" question is linked to the corresponding generic question of what ontological categories the items posterior to form-the compound and matter-fall under. In the case of the compound the answer seems simpler. The compound is an object-either a particular or token-object (like Socrates or Bucephalus) or a universal or type-object (like human or horse; Z.10, 1035b27-31 and ff.). It seems plausible to understand universal or type-objects as in some sense metaphysically 
parasitic upon particular or token-objects.

Similarly, matter-whatever it is precisely-seems to conform to this distinction: for there are token-materials (such as these particular written or uttered speech elements; or my own nasal matter) as well as type-materials (such as inky or air-en speech elements; or exercised human muscles). Metaphysics Z.10, 1035a9-17, offers the example of a syllable and the "material elements", the letters making it up. Further, 1035a17-b3 describes bones and flesh as the token matter into which a particular compound human perishes (see especially the example of Callias at 1035a33). Let us call objects or types of object, entities such as compounds and matter, 'type (a)' entities.

To understand the status of essence or form, it is helpful to return to Aristotle's striking identity and non-identity claims such as (1) and (2) made not only in Metaphysics Z.10-11 and H.3 (101035b31-1036a3; 1037a33-b7; 1043b14 and ff.) but also in Topics V.4, 133b31-36. Against the background of his understanding of universal compounds, the non-identity should be due to the fact that human is a universal compound, a type-object, which has an essence or form. Further, its essence or form is prior to, and so non-identical with, it. The soul, by contrast, is paradigmatically an essence or form and so does not have, but is the essence or form; it is identical with "its" essence or form.

Moreover, it is fair to note that there is a deeper difference between human and being a soul, or more generally between the (token or type) $F$ and (the essence/form) being $F$, in respect of logical grammar and ontology. The former is an object (this human or Socrates) or a type-object (human), whereas the latter is a what-it-is-to-be- $F$ ( to ti èn einai tō(i) F; to einai tō(i) $F$ ), an essence or a form. The most promising, if unconventional, manner in which to characterise an essence or form is as a way or mode of being for the (token or type) $F$-object. Indeed, the notion of a way or mode of being seems best to capture Aristotle's own terminology of 'what-it-is-to-be- $F$ '. Let us call ways or modes of being 'type (b)' entities.

Is talk of ways or modes of being excessively mysterious? Not so much, I think. Modern metaphysicians, such as E. J. Lowe, C. B. Martin, and J. Heil employ this conceptual apparatus seriously and, arguably, with considerable success. One reason why they posit ways or modes of being is that they aim sharply to distinguish their views of properties from trope theories, in which an object is identified with a bundle of particularised properties (or tropes). They insist, by contrast, that a property is simply a way in which, or how, an object is. There is no need for the present proposal to conceive essences or forms strictly as particular or individual ways of being, as Martin and Heil suggest in their account of properties (but nothing in my view rules out there being particular or individual ways of being). Nor is it necessary to identify, 
as Lowe does, a particular object or compound with its form. Indeed, this is an identity that my view explicitly and strongly denies in order to respect Aristotle's own non-identity claims such as (1). ${ }^{12}$

An Aristotelian way of being seems to be the ontological correlate of an open sentence such as ' $F x^{\prime}$ ' or ' uration", to use a Fregean turn of phrase. This seems to accommodate Aristotle's claim that an essence or form necessarily depends for its existence on some particular compound or other existing (unlike implausible, Platonist versions of essentialism). Second, this view of essence and form is sensitive to the deep, categorial difference that seems to obtain between type (a) and type (b) entities. Third, a way of being as such is not to be identified with an essence or form. The concept of a way of being is general enough to be distinct from that of an essence. For a way of being is not sufficient, by itself, to mark out an essence from a non-essence. After all, there are many ways of being - being pale, being sun-tanned, being sun-burnt, etc.- which may be ways for Socrates or for (members of) the human-type to be without being essential ways of being for them. Fourth, because ways of being are the ontological correlates of open sentences, the essentiality of a way of being can be conceived of as the real counterpart to an adverbial qualification or copula-modifier such as 'essentially': to be Socrates or to be (a member of) the human kind is to be essentially human. Fifth, this view also allows for Aristotelian notions such as potentiality or actuality to be the real-world parallels to corresponding copula-modifiers such as 'potentially/actually', 'in potentiality/actuality', or 'in respect of potential/actual being. Thus, for instance, to be the matter of a house-the house-buildable bricks, stones, and mortar-is to be potentially a house. Or to be an actual house, one that exemplifies the form and the final cause of being a house, is for the bricks, stones, and mortar to be actually arranged as a covering for the sake of protection of humans and their belongings from wind, heat, and rain (or something along these lines).

Most importantly, though, this view respects our intuition that an essence or form is ontologically prior to the items it is the essence or form of: for it makes the latter what they are but not conversely. This asymmetric relation of priority cannot be preserved by views which identify a token- or type-object with its essence or form. For, as pointed out earlier, this sort of

${ }^{12}$ Lowe does not understand essences or forms, but only particular properties, as modes of being. Rather, he identifies essences or forms with sortals, substance-kinds, such as human or horse-Aristotle's secondary substances in the Categories. In this respect he distances himself from the Aristotelian view I am defending at present. See (Lowe 2013), (Lowe $2012 \mathrm{~b}$ ) and (Lowe 2012a). For his identification of form with the compound also see (Lowe 1999). 
identity (a congruence and equivalence relation) would be symmetric, while the ontological priority relation is asymmetric, and no relation can be both symmetric and asymmetric (in the same way or sense). ${ }^{13}$ Understanding essence or form as a way of being emphasises at the outset the categorial distinctness and so the non-identity between a form and the corresponding compound. If so, it accommodates (or at least does not disregard) the intuitive idea that an essence or form is ontologically prior to (but not identical with) the token- or type-object it is the essence or form of. Needless to say, this result is in agreement with Aristotle's non-identity claims such as (1).

The aim of the present ontological digression is to clarify Aristotle's identity and non-identity claims (1) and (2) without giving up the definitional and essential sameness relations between a type (a) entity and its essence, the relevant type (b) entity. From the discussion of type (b) entities it seems clear that an essence such as being a human is identical with "its" essence, being a rational soul, in terms of which it is also defined: both the identity and the definitional claims, (2) and (3), are about just one entity, an essence or (essential) way of being. This is not to deny that being a human and being a rational soul are the same "in essence" or "in nature". Nor is it to give up the intuition that being a human is defined in terms of being a rational soul. Indeed, this is a case in which essential sameness and definition straightforwardly allow for identity.

In the case of the kind human and its essence, being a human, by contrast, (1) holds good because of the fundamental categorial and ontological diversity between type (a) and type (b) entities. The former is a kind, a typeobject, whereas the latter is an essence, an (essential) way or mode of being: how could they ever be identical? At the same time, though, (4) is correct: the kind human is defined in terms of its essence. This is equivalent to a claim of essential sameness between the two: for to be the kind is essentially nothing other than, or is the same in nature as, to be a human. By no means, however, is this sameness in nature or in essence equivalent to, or sufficient for, identity. ${ }^{14}$ To generate a corresponding identity claim, one would have

${ }^{13}$ For example, one might argue that while a (type of) object and its essence are identical, yet the essence is prior to the (type of) object in an epistemic way or sense in that it makes the (type of) object knowable or better known to us. This line of argument, however, involves a shift from an ontological sense of identity to an epistemic sense of priority.

${ }^{14}$ Hence, the present claim of essential sameness need not clash with Aristotle's own repeated claims in the Topics V.4, 133b31-6, and Sophistici Elenchi 24, 179a35-b1, that the F type of thing and being $F$, although the same, differ in being (einai) or in substance/essence (ousia). Nor is it necessary, because of these claims, to understand the relation between a (type of) thing and its essence as merely necessary co-extension between the respective terms. Rather, the idea is that the $F$ type of thing differs "in being" or "in substance" from being $F$ as the former is a type of object, while the latter is an essential way of being. They 
to use the device of the 'the' operator within (4) and derive something like 'human = the kind whose essence is to be a human'. This result also indicates that essential sameness and definition do not rule out certain related identity claims.

\section{Particular Compounds and their Essence}

Some modern metaphysicians find it difficult to appreciate the Aristotelian concern with what I have labelled 'type-objects', 'substance-kinds', or 'universal hylomorphic compounds' and the relation to their essence. They are primarily interested in, or even obsessed with, particular hylomorphic compounds, token-objects, such as Socrates or Bucephalus. It would be useful, then, to close our study by making some brief remarks about whether, and if so, how the present view applies to the relation between particular objects, such as Socrates, and their essence.

It seems that in the case of Socrates a non-identity claim analogous to (1) is more straightforwardly true:

(9) Socrates $\neq$ being a human. ${ }^{15}$

For, arguably, particular compounds such as Socrates just are not identical with their essences as the former are token-objects, whereas the latter are (essential) ways of being for these token-objects. Indeed, in the places where Aristotle puts forward (1) it seems plausible to interpret him as referring predominantly to the relation between particular compounds and their essences. This is not to deny that his remarks also apply to substance-kinds. Hence, in ( $\mathrm{T} 1)$ he contrasts the cases of (a/the?) circle and (a/the?) soul with intelligible or perceptible particular compounds (Z.10, 1036a1-3: kath' hekasta). In ( $\left.\mathrm{T}_{2}\right)$ the identity of (a/the?) curvature and being a curvature is introduced immediately after discussing the examples of Callias and (this concrete particular) snub-nose (Z.11, 1037a33ff.). Further, again in (T2), the non-identity of a compound and its essence seems to be exemplified by the case of Socrates (or things like him) and his essence. ${ }^{16}$ Similarly, the nonidentity claim made in $\left(\mathrm{T}_{3}\right)$ seems to be ultimately grounded on the idea that

are the same, however, in the following two respects: (a) necessarily, the very same items are members of the type $F$ and are instances of the way of being $F$ (i.e., the corresponding terms are necessarily co-extensive); and (b) being $F$ is the essential way of being for the $F$ type of thing.

${ }^{15}$ A basic question, at this juncture, is how to understand Socrates' essence, or being Socrates. I shall proceed on the assumption that particular substance compounds are essentially members of their corresponding substance-kinds, and so have the same essence as these kinds: being Socrates is simply to be a human.

${ }^{16}$ Ross (1924) and Jaeger (1957) emend this difficult sentence at Met. Z.11, 1037b5, into oud' ei kata sumbebèkos hen. Ross $(1924,205)$ reads this as follows: "Nor is a thing the same as its 
an essence or a form such as being a human or being a (rational) soul-an (essential) way of being-is not $a$ (concrete particular?) human being (H.3, 101043b2-4).

It is not necessary, however, to deny the possibility of defining particular compounds in some way comparable with (4). Socrates himself may be definable (perhaps in some attenuated notion of definability?) in terms of the essence or form of human, the substance-kind he is a member of (see Z.10, 1036a7-9: all' aei legontai kai gnōrizontai tō(i) katholou logō(i); Z.11, 1037a25-29: tēs sunolēs, tautēs de g' esti pōs logos kai ouk estin ... kata tēn prōtēn d' ousian estin, hoion anthrōpou ho tēs psuchēs logos). For instance:

(10) Socrates $=_{d e f}$ being a human (or being a rational soul).

It may even be the case that the kind's essence or form essentially involves matter of some appropriate sort. Thus, for example, being a human is being a rational soul. But being a human or being a rational soul may be essentially unspecifiable without a reference to (e.g.) being a body with tissues, bones, flesh, etc. structured in a certain fashion. ${ }^{17}$ Irrespective of our approach to this last question of whether essences or forms are pure or essentially matterinvolving, it seems clear that Socrates himself involves types of matter and material parts which are not essential to him. Perhaps these types of matter or material part belong to him only necessarily or even merely accidentally. It is necessary that Socrates have an epidermis with some complexion or other. But this is hardly one of his (or his kind's) essential features. Or Socrates is now having a sun-burnt nose. But this is only an accidental and ephemeral feature he has because he spent too much time philosophis-

essence if the thing be a compound of a subject with an accidental attribute". It is unclear how this sense can be extracted from the Greek. It also seems out of place for Aristotle to focus on the relation between a hylomorphic compound and an accidental compound consisting of it plus a non-substance attribute. The manuscript reading seems to make better sense as it stands: oude kata sumbebēkos hen. Socrates is neither identical with his essence (contrast how an essence or form is identical with "its" essence) nor coincidentally the same as it (contrast how Socrates is the same as the cultivated Socrates). The crucial connective oude can be read in two rather diverse ways. First: a particular compound is neither identical with its essence nor even coincidentally the same as it. In this construal, the relation between Socrates and his essence is lesser or weaker even than coincidental identity. This seems unattractive. It is more promising to adopt the second reading: a particular compound is neither identical with its essence nor merely coincidentally the same as it. Thus, Socrates is not identical with being a human. But nor is he merely coincidentally the same as being a human. Rather, there is an intermediate type of sameness, weaker than identity but stronger than coincidental sameness, which obtains in the case of Socrates and his essence. This would be our notion of essential sameness or/and definition.

${ }^{17}$ For a view of natural essences or forms as essentially matter-involving see (Peramatzis 2011), (Peramatzis 2014) and (Peramatzis n.d.). 
ing in the scorching Athenian sun yesterday. It is the presence of these extra, non-essential features which render Socrates non-identical with his (or his kind's) essence or form. For this essence just could not include any of Socrates' merely necessary or accidental features, whereas Socrates himself does indeed possess such features.

There are three important questions growing out of this view of particular compounds or token-objects. First, what is the relation between Socrates and his essence or form discussed at the end of Metaphysics Z.11 (1037b4-7)? It seems clear that Socrates is non-identical with his essence. Indeed, this is presupposed by our understanding of the non-identities in (1) and (9). But is it also the case that he is not even coincidentally the same as his essence in that the relation to his essence is "lesser" or "weaker" even than the relation between Socrates and (e.g.) his cultivation (or between Socrates and the cultivated Socrates)? Or does the end of Metaphysics Z.11 entail only that the relation between Socrates and his essence is not "simply" or "merely", but is more "exalted" and "stronger" than, the relation of coincidental sameness, even if not as strong as the identity holding between an essence or form and "its" essence, encapsulated in (2)? To this question our notions of essential sameness and definition enable us to return a neat answer. The strength of the relation between an item and its essence is stratified (whether in levels, or types, or degrees is not important for present purposes). Thus, the strictest or strongest relation, identity, obtains between an essence or form and "its" essence. The weakest, coincidental sameness, applies to an object and an accidental compound consisting of this object plus a merely accidental feature belonging to it (or between an object and its (having an) accidental feature). There is, however, tertium quid, a relation of intermediate strength: essential sameness and definition. This is the relation between Socrates and his essence, being a human (or, for that matter, between the substance-kind human and its essence, being a human).

The second question is about the manner of involvement of extra (material) items in Socrates, over and above those which may be essentially involved in his (or his kind's) essence or form. Obviously, any treatment of this question ought to be sensitive to one's attitude towards the previous question. It seems, however, that Socrates' own (non-essential) matter should not be conceived as somehow essentially constituting Socrates. For, while several (perhaps gradually even all) of the bits, tokens, or even (some) types of matter or material part which Socrates possesses at some stage(s) of his "career" could be lost with or without replacement (as the case may be), he could persist as essentially the same (kind of) object. It is certainly true that this last claim holds good on the assumption that Socrates' essence is what makes Socrates essentially a particular object of a specific type (or a specific 
type of particular object). The claim would have to be drastically qualified (perhaps even dropped altogether) if we understood Socrates' essence as what makes Socrates essentially this concrete, particular, or token object, with a synchronic and diachronic identity exclusive to him alone.

Third, what is the difference between the extra types of matter had by Socrates and the (material or formal) features making up his (or his kind's) essence? This question is clearly related to the second question just discussed in the previous paragraph. But, while the second question was about the way in which (non-essential) material items are involved in a particular compound, this third question is about the nature of these material items themselves, and their difference (if any) from the items included in the essence or form being a human or being a rational soul. One could reply that the items which are part of the essence or form being a human may be material in some sense but are more generically specified than Socrates' (non-essential) matter. Or, to fill in some of the gaps inherent in this reply, an essence or form may involve material features but always specified in a way which invokes (for instance) formal, functional, or goal-directed characterisations. Thus, for example, being a human or being a rational soul may (essentially) include being bodily or being made up of tissues, flesh, bones, etc. arranged in a certain fashion. These items, however, are never crudely material, as it were, but are always characterised with the help of additional non-material descriptions: for instance, being a body which is an instrument for realising a certain sort of rational life (a putative function or a telos). Alternatively, one might argue that even if material items are present in an essence or form, they are ultimately understood only or primarily in terms of their formal, functional, or telic features. If so, they are somehow fully reducible to non-material, form-related entities. By contrast, the (non-essential) matter had by Socrates himself would be either concrete token-materials, or specific types of perceptible matter/material part (or both): Socrates' very own snub nose; the snub type of nasal flesh that he, Theaetetus, and other snub-nosed humans share, etc.

A further, more parsimonious, and perhaps more attractive, option would be to understand definitions and essential sameness claims about Socrates (such as (9) and (10)) analogously to corresponding claims about the kind human (such as (1) and (4)). In this view, the items involved in Socrates' essence-whether material or purely formal-are precisely those found in the relevant kind's essence or form. Socrates is essentially a member of the kind human, and his essence is the essence of that kind: to be a human. Indeed, given (2) and (3), to be a human for Socrates is to be a rational soul, with whatever other essential features this essence or form encompasseswhether material or/and formal. 
This suggestion could be set out using the device of the 'the' operator deployed earlier. Despite the non-identity of Socrates and being a human, codified in (9), the definition of Socrates as being a human (10) is correct, and can be conservatively modified into:

(11) Socrates ${ }_{d e f}$ the token-object whose essence is to be a human (or to be a rational soul).

This straightforwardly entails the related identity claim:

(12) Socrates = the token-object whose essence is to be a human (or to be a rational soul).

For how could Socrates not be identical with a relevant concrete token-object that has the essence or form being a human? This view implies that particular compounds are essentially just members of their substance-kind or instances of their essence or form. Moreover, just as in the case of the relevant universal compound human, it does not require that the items involved in Socrates' essence (whether material or purely formal) are dramatically different from what being a human (or being a rational soul) consists in. Put simply, just as human is essentially a type-object that has the essence or form being a human, similarly Socrates is essentially a token-object that has the same essence, being a human. If so, both universal and particular compounds are the same in essence or in nature as their essence or form, even if not identical with it. This is also congenial to an understanding of Aristotelian definition which is not constrained by the Procrustean identity requirement. A definition such as (10) does not entail, nor is it equivalent to, the identity 'Socrates = being a human'. Hence, the definiens being a human could be prior to the definiendum, Socrates. Moreover, this result vindicates the claim made towards the beginning of the present section that there is an analogue of the non-identity stated in (1) which obtains in the case of particular compounds such as Socrates: our (9). While Socrates is defined in terms of being a human, he is non-identical with but essentially the same as this essence.

\section{Acknowledgements}

Earlier versions of this paper were presented at seminars in Oxford. I am indebted to Lucas Angioni, David Bronstein, Laura Castelli, David Charles, Brian King, Sabina Lovibond, Steven Methven, and Stephen Williams for helpful comments. Thanks are also due to the editors of the Studia Philosophica Estonica for their extremely useful feedback. 


\section{Bibliography}

Charles, D. (2011). Some remarks on substance and essence in Metaphysics Z.6, in K. Ierodiakonou and B. Morison (eds), Episteme etc.: Essays in Honour of Jonathan Barnes, Oxford University Press, Oxford, pp. 151-171.

Jaeger, W. (ed.) (1957). Aristotelis Metaphysica, Oxford Classical Texts, Oxford University Press, Oxford.

Lowe, E. J. (1999). Form without matter, in D. S. Oderberg (ed.), Form and Matter: Themes in Contemporary Metaphysics, Blackwell, pp. 1-21.

Lowe, E. J. (2008). Two notions of being: Entity and essence, Royal Institute of Philosophy Supplement 62: 23-48.

Lowe, E. J. (2012a). Asymmetrical dependence in individuation, in F. Correia and B. Schnieder (eds), Metaphysical Grounding: Understanding the Structure of Reality, Cambridge University Press, Cambridge, pp. 214-233.

Lowe, E. J. (2012b). A Neo-Aristotelian substance ontology: Neither relational nor constituent, in T. Tahko (ed.), Contemporary Aristotelian Metaphysics, Cambridge University Press, Cambridge, pp. 229-248.

Lowe, E. J. (2013). Neo-Aristotelian metaphysics: A brief exposition and defence, in E. Feser (ed.), Aristotle on Method and Metaphysics, Palgrave Macmillan, pp. 196-205.

Peramatzis, M. (2011). Priority in Aristotle's Metaphysics, Oxford University Press, Oxford.

Peramatzis, M. (2014). Matter in scientific definitions in Aristotle, Oxford Handbooks Online, Oxford University Press, New York.

Peramatzis, M. (n.d.). What is a form in Aristotle's hylomorphism. Unpublished manuscript.

Ross, W. D. (ed.) (1924). Aristotle. Metaphysics, Oxford University Press, Oxford. Translated by W. D. Ross.

Shalkowski, S. A. (2008). Essence and being, Royal Institute of Philosophy Supplement 62: 49-63.

Zylstra, J. (2014). Dependence and fundamentality, Studia Philosophica Estonica 7.2: 5-28. 